\title{
TERRITORIALIDADE E NEGOCIAÇÃO IDENTITÁRIA: O QUESTIONAMENTO DO LAR EM BROWN GIRL, BROWNSTONES, DE PAULE MARSHALL
}

Denise Almeida Silva

\begin{abstract}
RESUMO
A partir da análise da representação de migrantes afro-caribenhos em Nova Iorque no romance Brown girl, browstones, de Paule Marshall, analiso, neste ensaio, o modo como a experiência do lugar, e em especialmente a vivência e imaginação de lar, afeta a construçáo identitária. Após a justificativa inicial da abordagem escolhida, defino lar e sua influência na formação das cosmologias estruturantes do indivíduo, passando, então, à análise da obra.

PALAVRAS-CHAVE: identidade, territorialidade, Paule Marshall.
\end{abstract}

\section{Introdução}

1 territorialidade enquanto palco e constituinte das relaçóes humanas tem ocupado lugar de destaque nas pesquisas da contemporaneidade. Se, como Doreen Massey raciocina, o espaço não existe antes de identidades/entidades e de suas relaçóes, então tanto as relaçóes quanto a espacialidade são constitutivas, construídas em conjunto. Uma vez que se adote esse olhar, em que identidade e espaço estão profunda e mutuamente associados, importa a maneira como se concebe espaço: tal concepção afeta as cosmologias estruturantes do indivíduo, modelando seu entendimento e, consequentemente, sua atitude frente aos outros e sua forma de praticar o sentido de lugar. ${ }^{1}$

1 MASSEY, Doreen. Pelo espaço: uma nova política da espacialidade. Rio de Janeiro: Bertrand Brasil, 2009. p. 16-35. 
A interdependência mútua entre espaço e construção identitária é intensificada e tornada ainda mais complexa em contextos migratórios, nos quais o indivíduo, membro de comunidades que se intersectam, divide-se entre múltiplos apegos, frequentemente oscilando entre um movimento de partida e retorno entre o que costumava chamar de lar e o lugar a que deve atribuir este estatuto no presente.

Essa renegociação de identidades, fundamental à migração, ocupa lugar de destaque na escrita de mulheres negras do Caribe. Afinal, movimentos diaspóricos a tal ponto afetaram a região que, como Hall destaca, todos os que ali estão pertenceram, originalmente, a outro lugar. ${ }^{2}$ A colonização da região pela Espanha, Países Baixos, Inglaterra e França equivaleu, no dizer do pesquisador jamaicano, à verdadeira violação: a terra - não vazia, já que originalmente habitada pelos Caribes e Arawaks - sofreu esvaziamento sob a ação do colonizador branco. Uma vez dizimados os habitantes autóctones, interesses comerciais impuseram a entrada de negros escravos, e, mais tarde, no século XIX, de trabalhadores asiáticos. Tẫo grande foi a importação de escravos no Caribe que estes, e seus descendentes, vieram a sobrepujar a população colonizadora europeia. Mais recentemente, movimentos migratórios caribenhos - agora voluntários especialmente para a Europa, como no caso da migração para a metrópole da geração Windrush, e para a América - têm ocorrido com certa regularidade. A esse respeito, vejam-se, por exemplo, registros de 2009, de acordo com os quais três milhões e meio de caribenhos emigraram para os Estados Unidos, 69\% dos quais passaram a residir em Nova Iorque e na Flórida. ${ }^{3}$ Os caribenhos representados no primeiro romance de Paule Marshall, Brown girl, brownstones (1953) remetem à experiência migrante durante a Guerra Fria e a II Guerra Mundial.

A vivência da migração também não é estranha a Paule Marshall. Nascida em Nova Iorque, filha de imigrantes do Caribe, Marshall desenvolveu aguda consciência de sua geografia pessoal por meio da simultânea vivência de um lar caribenho na América e da terra que fora o primeiro lar de seus pais. Não surpreende, assim, que em Brown girl, brownstones identidade e territoria-

2 HALL, Stuart. "Pensando a diáspora: reflexôes sobre a ter ano exterior". In: Da diáspora: identidades e mediaçóes culturais. Belo Horizonate/Brasília: UFMG; UNESCO, 2003. p. 30 .

3 MCLABE, Christen. "US in focus: Caribbean immigrants in the United States". Migration information Souce. Washington, DC, 2011. http://www.migrationinformation.org/usfocus/ display.cfm? $\mathrm{ID}=834,29 / 02 / 2012$. 
lidade ocupem lugar de destaque: a protagonista, Selina, como Paule Marshall fruto da diáspora caribenha na América, tem de negociar sua identidade no contexto de sua tripla herança cultural afro-americana-caribenha, enquanto oscila entre lealdade ao pai, Deighton, eternamente saudoso de seu Barbados nativo, e à mãe, Silla, apegada à terra de acolhida.

Ao início do romance, quando Selina, curiosa e encantada, escuta as reminiscências do pai sobre sua ilha natal, pergunta-lhe: "What is it like home?" " Tomo essa interrogação como a questão norteadora deste ensaio, investigando como, no romance, as construçóes identitárias se desenvolvem em conexão com a construção ou descontrução do significado de lar por Selina e seus pais. Este é um tópico relevante, não só dada a centralidade das discussões, nesse romance, acerca de lar e de seu símbolo material mais visível - a casa -, como da estreita relação entre esse espaço e a identidade de seus ocupantes, um fato já sugerido pelo próprio título do romance. Ademais, como Carole Boyce Davies observa, ${ }^{5}$ nas obras de escritoras americanas nascidas da diáspora afro-caribenha, a representação da casa como fonte de autodefinição ocorre com certa frequência, como metáfora para o eu e seus locais de autoidentificação.

\section{Quando o lugar se transforma em lar}

Embora o conceito de lar tenha sido primeiramente definido a partir da noção de espaço, esta é uma conceituação bastante estreita. Theano Terkenli ${ }^{6}$ chama a atenção para o fato de que lugar existe em diferentes escalas, e pode abranger desde uma cadeira favorita ou o pátio de uma casa até um país ou o globo terrestre. Longe de ser uma mera noção geográfica, lar aponta, para além do contexto físico ou espacial, para condiçóes habituais e sociais. Está, assim, intimamente relacionado ao fator humano, resultando do modo como os indivíduos interagem com seu ambiente por meio de comportamentos adquiridos pessoal e/ou culturalmente. Em sua dimensão social, a ideia de lar

\footnotetext{
MARSHALL, Paule. Brown Girl, Brownstones. New York: Dover, 2009. p. 8.

5 DAVIES, Carole Boyce. Black women, writing, and identity: migrations of the subject. New York: Routledge, 1994, p. 126.

6 TERKENLI, Theano S. "Home as region". Geographical Review, v. 85, n. 3, Louisiana, Jul. 1995 , p. 325.
} 
associa-se ao desenvolvimento de círculo de relaçóes que validam o indivíduo como ser humano, a começar pela mãe - o primeiro lar - e alargando-se em círculos cada vez maiores e mais complexos, que expandem e reforçam essa noção, que pode ser delineada, também, a partir de parâmetros étnicos, nacionais, cívicos ou ideológicos.

A geografia do lar é construída na interface entre o eu e seu mundo e através, também, da dicotomia "nós” x "eles", representada, no romance, não só através do contraste entre os valores brancos e negros, como por meio de diferenças dentro da própria comunidade negra, tipificadas por Deighton e Selina Boyce e os migrantes que subscrevem a visão de cada um desses personagens.

Terkenli descreve o que chama de regiôes-lar (“home regions”), distintas das demais devido a escolhas pessoais e/ou coletivas, e estruturadas de acordo com objetivos, costumes, desejos e circunstâncias específicos. Como fica claro, já a partir dessa breve definição inicial, tais lugares são geográfica e culturalmente construídos, e historicamente contingentes, e sua existência vem atender a necessidades fundamentais dos indivíduos e grupos humanos. Contudo, convém ressaltar que tais localidades, tanto a nível individual como coletivo, sofrem constante construção e desconstrução, uma vez que a atribuição de valor e significado a um lugar por parte de um indivíduo é subjetiva, e expressão de intencionalidade em contexto histórico específico. No caso de atribuição coletiva do valor de lar a uma região, como em comunidades diaspóricas semelhantes à enfocada no romance, experiências intersubjetivas compartilhadas subjazem a essa valoração.

A imaginação popular costuma associar lar a ambientes domésticos em que há harmonia e bem estar; de fato, a provisão de um refúgio, e de um contexto viável para autoidentificação, que sirva como quadro de referência, são algumas das necessidades básicas providas por essa ambiência. Lugar transforma-se em lar na presença de investimento emocional e material contínuo em um contexto que o indivíduo possa personalizar e com o qual se identifique por meio do exercício de algum tipo de controle.

Repetição é outro elemento fundamental nessa transformação. Ao longo do tempo, o ser humano desenvolve muitas rotinas comportamentais, cognitivas e afetivas. Processo similar ocorre a nível grupal, na criação de lares coletivos, configurados como herança cultural compartilhada e/ou a partir da mesma terra de origem. Embora rotinas não sejam sempre geograficamente 
específicas, o indivíduo ou o grupo recorre a esses padróes repetidamente, porque representam estratégias de sobrevivência e de satisfação pessoal que resumem liçóes consolidadas acerca de tentativas, erros e sucessos passados, e que passam a integrar o conceito de lar por representar pontos familiares de referencia no tempo, espaço e sociedade.

Uma vez que a atividade simbólica é indispensável à estruturação das relaçôes do homem com o mundo, o indivíduo, ao ocupar o espaço, usa símbolos que o transformam em lugar; lugar e contexto ocupam espaço proeminente na transformação de lugar em lar. Como parâmetro que subjaz a todas as relaçóes ente o homem e o seu ambiente, a noção de lar, altamente simbólica, faz-se presente tanto quando alguém se desloca do conhecido para o desconhecido, como no movimento contrário. Quando um bairro ou cidade representa lar para uma comunidade, seus vários elementos constituintes e características tornam-se símbolos de lar. Como símbolo de experiências intersubjetivas, as representaçóes do lar tornam-se representaçóes do eu ou do grupo. ${ }^{7}$

Como ser histórico, o homem sente-se em paz consigo mesmo quando entretém familiaridade tanto com suas ações passadas como com as atividades, sentimentos, preocupações e aspirações do momento, as quais se ancoram no eu. Em estudo fenomenológico dos valores de intimidade do espaço interior, Gaston Bachelard ressalta a abundância de imagens e vivências que se concentram em torno da casa, ${ }^{8}$ e levanta a hipótese de que imagens dispersas, bem como um corpo de imagens que conformam essa noção, não se referem a localidades especificas, mas representam a confluência de todas as casas, vividas ou imaginadas, em que o individuo encontrou o menor abrigo: como o pensador francês resalta, todo o espaço realmente habitado traz a essência da noção do lar. Assim, já não é somente em sua positividade que a casa é verdadeiramente vivida, nem somente no presente que seus benefícios se tornam conhecidos: vive do dia a dia, na narrativa da história humana, e a cada morada retornam as lembranças das moradas antigas. $\mathrm{Na}$ construção do conceito, memória e

7 TERKENLI, Theano. Op. cit., p. 324-328.

8 Bachelard parece empregar casa não apenas com referência ao aspecto material, mas como um sinônimo, mais ou menos livre, de lar, já que enfatiza seu valor como lugar de intimidade e proteção, destacando as características maternas que a tornam um refúgio para o homem. Além disso, descreve tanto o senso de continuidade como a estabilidade dela decorrente como características constitutivas da casa. 
imaginação trabalham em cooperação mútua, constituindo uma comunidade de memória e imagem. Analiso, a seguir, a maneira como uma tal comunidade imaginativa é construída em Brown girl, brownstones a partir das memórias migrantes de Barbados e da experiência diária da vivência do lar no país de acolhida.

\section{A (des)construção do lar em Brown girl, brownstones: pertencimento e propensão afiliativa, entre Barbados e Nova Iorque}

Inicio esta sessão retomando o pensamento de Bachelard. Ao enfatizar a construção imaginativa do lar a partir do acúmulo de vivências e do atravessamento de lembranças, o pensador diz: "Os verdadeiros bem-estares tem um passado. Todo um passado vem viver, pelo sonho, numa nova casa. [...] Quando, na nova casa, retornam as lembranças das antigas moradas, transportamo-nos ao país da Infância Imóvel, imóvel como o Imemorial."9 A influência de memórias do lar da infância na avaliação de contextos presentes é bem perceptível no romance de Paule Marshall, e isso não somente com relação às fixaçóes de felicidade como com relação a sua negação, ou seja, à persistência de memórias infelizes.

Brown girl, brownstones é ambientado em Nova Iorque, em 1939, e uma parte considerável do romance tem como cenário a casa dos Boyce, uma das muitas casas de pedra marrom em Chauncey Street, no Brooklyn. No período transicional evocado no romance, a rua, que tinha inicialmente sido habitada pelos holandeses, e depois por imigrantes escoceses e irlandeses, é gradualmente abandonada pela população branca, e vem a ser o lar dos imigrantes das Índias Ocidentais, especialmente dos barbadianos pobres, que jamais haviam possuído casa própria em seu país de origem. Para essa população, a aquisição de bens imóveis equivale a sucesso. Assim, os membros da família Boyce são apresentados, um a um, em conexão com a casa e/ou suas memórias acerca do que significa, para eles, o lar. Este termo assume conotaçóes diferentes para cada um dos Boyce.

O primeiro personagem a ser descrito é Selina, e a opção de apresentá-la para o leitor quando entregue a devaneios sobre a casa não é apenas uma

9 BACHELARD, op. cit, p. 25. 
maneira de caracterizá-la como uma típica adolescente - sonhadora, insatisfeita com sua aparência, e enfrentando problemas de pertencimento (no seu caso em particular, complicado pelo preconceito racial e experiência migrante) - mas também um reconhecimento do valor da imagem onírica da casa em associação com raízes e formação de identidade. Bachelard observa que a memória não registra a duração concreta: é pelo espaço e no espaço que ela se conserva. O filósofo francês declara: "as lembranças são [...] tanto mais sólidas quanto mais bem espacializadas. [...] Mais urgente que a determinação de datas é, para o conhecimento da intimidade, a localização nos espaços da nossa intimidade".

Atribuindo à casa, como benefício maior, a possibilidade de abrigar o devaneio, Bachelard é taxativo na avaliação da positividade dessa atividade mental:

Só as experiências e os pensamentos sancionam os valores humanos. Ao devaneio pertencem valores que marcam o homem em sua profundidade. $\mathrm{O}$ devaneio tem mesmo um privilégio de autovalorização. Ele usufrui diretamente de seu ser. Então os lugares onde se viveu o devaneio reconstituem-se por si mesmos num novo devaneio. É exatamente porque as lembranças das antigas moradas são revividas como devaneios que as moradas do passado são imperecíveis dentro de nós. ${ }^{10}$

Como algo fechado, uma casa guarda lembranças, conservando-lhes seu valor de imagem; Marshall explora ainda outra possibilidade associada ao lugar de habitação: o devaneio a partir não da experiência vivida, mas da imaginação de outras possíveis histórias vitais. Ao início do romance, parece a Selina Boyce, então uma adolescente, que a casa está viva. Uma longa descrição segue os seus movimentos e o desenrolar de seus pensamentos enquanto ela, do alto do piso superior, acredita ouvir a respiração de sua casa, bem como seus silêncios. Selina é particularmente atraída por estes últimos, pois eles lhe permitem penetrar no passado escondido da casa, e seguir os movimentos de seus antigos habitantes brancos:

10 BACHELARD, op. cit., p. 26, grifo do autor. 
She rose, her arms lifted in welcome, and quickly the white family who had lived here before, whom the old woman upstairs always spoke of, glided with pale footfalls up the stairs. Their white hands trailed the banister; their mild voices implored her to give then a little life. And as they crowded around, fusing with her, she was no longer a dark girl alone and dreaming at the top of an old house, but one of them, invested with their beauty and gentility. She threw her head back until it trembled proudly on the stalk of her neck and, holding up her imaginary gown, she swept downstairs to the parlor floor. ${ }^{11}$

Havendo se deslocado ao longo do hall de entrada, e entrado na sala, revestida de mobiliário pesado deixado pelos brancos, Selina náo pode evitar um sentimento de deslocamento. Como não se identifica com a mobília, pensa na casa como se fosse uma espécie de museu, que engloba tanto objetos materiais como as vidas de todos os que por lá tinham passado. Persiste, nesse devaneio, o valor da casa enquanto ambiente fechado e preservador de histórias vitais, mas esse valor é afetado pelo fato de que as imagens que remetem a essas histórias não pertencem aos que agora ali vivem, ou seja, há uma fratura entre história imaginada e história vivenciada. Tal dissociação entre observador e objeto observado, normal em um museu, é inesperada em um ambiente doméstico, onde a continuidade de investimento temporal e emocional normalmente promove conhecimento, familiaridade e controle.

Uma vez que imaginação e realidade vividas não se unem na formação de comunidade imaginativa, o reflexo do rosto de Selina no espelho da sala parece-lhe a tal ponto inapropriado que a figura do museu é imediatamente substituída, em seus pensamentos, por outra, a do templo, no qual ela não tem o direito de estar: "She didn't belong here. She was something vulgar in a holy place. The room was theirs" 12 Como o contexto deixa claro, o pronome "theirs" refere-se aos brancos: Selina parece ter introjetado aquela epidermalização da negritude tão bem descrita por Fanon, através da qual o negro,

11 MARSHALL, Paule. Brown girl, brownstones. New York: Dover, 2009. p. 2-3.

12 MARSHALL, op. cit., p. 3-4. 
repetidamente inferiorizado, desprezado e ignorado pelo branco, acaba não só naturalizando como aceitando sua suposta inferioridade. Por outro lado, o gesto afiliativo, simbolizado pela imitação, ainda que imaginativa, do porte e vestuário dos moradores brancos, lembra a atitude do negro que veste a máscara branca para ser aceito pelo outro, aludida já no título da clássica obra do psiquiatra jamaicano, Pele negra, máscaras brancas. ${ }^{13}$

A casa é, segundo Bachelard, uma das maiores forças para a integração dos pensamentos, lembranças e sonhos do homem. Passado, presente e futuro emprestam-lhe dinamismos diferentes, que tanto podem se opor como se estimularem mutuamente; nesse processo, Bachelard reserva ao devaneio o papel de princípio de ligação entre as vivências e expectativas abrigadas por um individuo. $\mathrm{O}$ pensador admite, contudo, que uma metafísica completa abrange o inconsciente e o consciente, mas considera que a metafísica da consciência é de segunda posição, já que passa por cima das preliminares em que o ser humano é colocado em um bem-estar que é, primitivamente, associado ao ser. Tal metafísica manifesta-se a partir de experiências em que o indivíduo, expulso de casa, acumula a hostilidade dos homens e do universo. ${ }^{14}$

O dinamismo cambiante resultante da interação entre vivências e aspirações passadas, presentes e futuras é particularmente visível nos diferentes significados que "lar" e a posse de um imóvel têm para Deighton e Silla Boyce. No contexto geral do romance, "lar" aponta para Barbados, a ilha de onde a maioria dos habitantes do bairro procede. No seio da comunidade, o nome do país não necessita ser pronunciado: é naturalmente subentendido quando quer que pessoas ou objetos sejam descritos como sendo lá de casa - "from home". Do homem de Suggie diz-se, em descrição breve, que vem "from home"; as jovens são tipicamente descritas como portando "pulseiras de prata que vieram lá de casa" ("silver bangles which come from home”), e Deighton Boyce julga que as crianças da diáspora barbadiana criadas em Nova Iorque não apreciam tanto as atividades ao ar livre como ele as apreciara quando menino, razão pela qual essas crianças atuais não se comparam com as "lá de casa” ("back home”). Semelhantemente, Florrie Trotman, uma das mais antigas amigas de Silla, acha que as crianças de

13 FANON, Frantz. Pele negra, máscaras brancas. Salvador: EDUFBA, 2008. 194 p.

14 BACHELARD, op. cit, p. 26-27. 
Nova York são muito moles (“soft") e não gostam de trabalhar, uma declaração que é melhor compreendida quando situada no quadro do regime de abusivo trabalho infantil a que essa mulher, semelhantemente a Silla Boyce, deve ter sido submetida. ${ }^{15}$

Estes exemplos - apenas algumas das muitas ocorrências do uso do termo lar, no romance, com referência à ilha nativa - atestam o fato, também apontado por Bachelard, de que "a casa natal é uma casa habitada": esse local inscreve-se fisicamente em seus habitantes como um conjunto de hábitos orgânicos. Ademais, o espaço que ocupou o papel de primeiro lar é mais que um centro de moradia: a casa natal é um centro de sonhos. ${ }^{16}$

Perseguindo esse racocínio até as suas últimas consequências, não parece desmesurado pensar, também, essa comunidade mnemônica em relação à dimensão pública de lar. Segundo Terkenli, aspectos do lar que parecem mais ameaçados pela compressão espaço-temporal, individualismo, alienação e impessoalidade conduzem a uma reavaliação da comunidade, região ou lugar ancestral que assegura distintividade ao indivíduo. ${ }^{17}$

O poder da memória pátria na formulação do conceito de lar é exemplificado através da experiência vital de Deighton e Silla Boyce. Como Deighton comenta com sua filha Selina, ele e a esposa experimentam importantes diferenças em Barbados:

I's a person live in town and always had plenty to do. I not like yuh mother and the 'mounts of these Bajan that come from down some gully or up some hill behind God back and ain use to nothing. 'Pon a Sat'day I would walk 'bout town like I was a full-full man. All up Broad Street and Swan Street like I did own the damn place. ${ }^{18}$

Além de diferenças relativas a uma educação urbana e rural, a infância dos Boyce diferiu imensamente com relação ao tempo despendido em trabalho e lazer, um fato que provoca avaliaçóes diferentes quanto a sua terra natal. En-

15 MARSHALl, op. cit, p. 29; 2; 7;55-56.

16 BACHELARD, op. cit., p. 33-34.

17 TERKENLI, op. cit., p. 333.

18 MARSHALL, op. cit., p. 7. 
quanto Deighton relembra momentos alegres, jogando críquete ou futebol em Kensington, ou tomando banho de mar em Christ Church, onde residiam os brancos ricos, as memórias de infância de Silla evocam trabalho duro. Quando menina, aos dez anos, costumava trabalhar mais arduamente do que muitos adultos, como membro da Third Class, um grupo de crianças que cumpria longa jornada de trabalho nos canaviais, do amanhecer ao pôr do sol, sob o escrutínio de uma supervisora que náo permitia às crianças qualquer pausa ou lazer.

Em resposta ao questionamento de Selina sobre como era seu lar, Deighton resume: "Barbados is poor-poor but sweet enough. That's why I going back". ${ }^{19}$ A definição de Silla, entretanto, é amarga e cheia de resentimento: "That's Bimshire. ${ }^{20}$ One crop. People having to work for next skin to nothing. The white people treating you like slaves and we taking it. The rum shop and the church join together to keep we pacify and in ignorance. That's Barbados" (id, p. 58).

Ainda que Selina fosse muito jovem ao inicio do romance, como o demonstram seus devaneios adolescentes em torno da casa e a ingenuidade quase infantil com que absorve as memórias do pai sobre Barbados, não lhe escapa o comportamento contrastante dos pais quando se trata da avaliação da terra natal:

The image of her father swaggering through the town as a boy and bounding on the waves in some rough game slanted across that of the small girl hurrying from the dawn ghosts with the basket on her head. It seemed to Selina that her father carried those gay days in his irresponsible smile, while the mother's formidable aspect was the culmination of all that she had suffered. ${ }^{21}$

Não surpreende, assim, que, apesar de ambos os Boyce adotarem o termo "lar" para se referir a Barbados, Silla não pensa a ilha natal como um lugar para se viver. Baseada em suas memórias da infância, ela julga que, lá, indiferentemente de quanto se trabalhe, "you gon be poor all yuh life". Essa falta de perspectivas destrói qualquer esperança de progresso, e a torna um ser totalmente desiludido: "You does stop trying after a time.[...] You does kind of die inside..."22

19 MARSHALL, op. cit., p. 8.

20 Bimshire é uma variante para Barbados, usada pela população local.

21 MARSHALL, Id., ibid., p. 39.

22 MARSHALL, Id., ibid., p. 58. 
A América, por outro lado, é vista pela Sra. Boyce como a terra da oportunidade. Apesar da discriminação e do trabalho árduo, julga que esse é um lugar onde se pode ser bem sucedido. Sua amiga Iris é a prova de que, se qualquer Bajan ${ }^{23}$ aproveitar as oportunidades ao máximo, a América lhes oferecerá padrão de vida superior ao que estaria a seu alcance em Barbados. Seu marido fora o primeiro Bajan a adquirir uma casa, devido às oportunidades de emprego oferecidas aos negros durante a administração de Roosevelt.

Conquanto, tanto quanto qualquer outro membro da comunidade negra do Brooklyn, Deighton Boyce desejasse alcançar sucesso, e, como todos os outros, equacionasse sucesso a um padrão de vida semelhante ao da população branca, ao invés de meramente pretender comprar uma casa, seu objetivo era alcançar reconhecimento e um alto salário que lhe permitisse comprar tudo do melhor:

Once I get started I gon make ' nough money and then these Bajan with their few raw-mouth houses will see what real money is! But I wun get like them, not me! Everybody gon say: "Deighton Boyce is one man that makes good money and lives good. He wear the best of clothes. He eat the finest. He rides in the swellest cars.' That's the way a man does things...24

Como está implícito na citação acima, comprar uma casa é também parte da agenda de Deighton. A imagem de sua propriedade futura está bem delineada em sua mente, embasada no que ele parece considerar o estilo de habitação de luxo em sua terra natal. Sua casa ideal seria construída com pedras brancas, e teria altas colunas, também brancas, como um templo, além de um salâo e uma sala de jantar cheia de vidros e flores. Seus planos de construção são desenvolvidos em oposição a tudo o que informa a sua noção de um casa pobre: "And we gon live in style, mahn. No little board and shingle house with a shed roof to cook in. We gon have the best now". ${ }^{25}$

$\mathrm{Na}$ verdade, a casa dos sonhos de Deighton marcadamente contrasta

23 Bajan é um gentílico para barbadiano. A palavra é uma variante de Badian, uma forma abreviada de Barbadian.

24 MARSHALL, op. cit, p. 71.

25 MARSHALL, Id., ibid., p. 9. 
com a tradicional habitação dos trabalhadores de Barbados, a shattel house, construída inteiramente de madeira e montada sem pregos. Essas casas, bens móveis, são facilmente desmontáveis, uma vez que seus proprietários, contratados para trabalhar nas fazendas, normalmente se deslocam de um lugar para outro. Assim, a casa planejada por Deighton, que seria construída de pedra e ricamente decorada, simboliza tanto seu desejo de fixação em sua terra natal como a possibilidade de fazê-lo em grande estilo.

Ao contrário da maioria das pessoas em sua comunidade, Deighton acredita que um homem negro não precisa aceitar empregos braçais, submeter-se à longa jornada de trabalho, nem ostensivamente demonstrar humildade para com o homem branco. Quando questionado de que outra forma um homem de cor poderia progredir, ele expóe sua fórmula: é necessário treinamento especializado. Segundo planeja, depois de concluir um curso de contabilidade por correspondência, estará qualificado para um emprego com ótimo salário. Mais tarde, quando esse plano falha, pois a qualificação não extingue o preconceito contra o homem de cor, Deighton espelha-se no sucesso dos músicos negros, e inicia aulas de trompete. Seria respeitado como Louis Armstrong e, Erskine Hawkins; os brancos implorariam para que tocasse para eles.

Além de diferir de sua comunidade quanto ao real significado do sucesso, e ao método para alcançá-lo, a visão Deighton sobre o lugar onde construiria uma casa, escolhida como símbolo e prova de conquista, também não coincide com o preferido pelos membros de sua comunidade. A América, vista quase universalmente por seus pares como terra da oportunidade, é, para ele, apenas o lugar para conseguir o dinheiro que lhe permitiria voltar para Barbados, este sim, seu lar. Assim, enquanto seus conterrâneos do Brooklyn estão envolvidos na compra de casas, Deighton Boyce apenas recorre à locação, porque o seu verdadeiro objetivo é comprar boa terra "em casa".

Nesse cenário, a notícia de que Deighton Boyce herdara propriedade em Barbados, e sua obstinada recusa em vendê-la e aplicar o dinheiro na compra de uma casa em Nova Iorque torna-se o ponto nodal a partir do qual surge um conflito no romance. Em casa, as fidelidades estão divididas: Selina, mais sintonizada com os valores de ser, apoia o pai, e claramente se identifica com seu país de origem ao ponto de chamá-lo de lar. Já a irmã de Selina, Ina, mais inclinada a tirar todas as vantagens possíveis de cada oportunidade, e mais orientada às posses mateirias, alia-se a sua mãe. 
Logo críticas a Deighton ultrapassam os limites da casa dos Boyce, unindo-se às observaçóes desesperadas e furiosas de Silla sobre sua falta de ambição. Percy Challenor, imigrante colega de trabalho de Deighton, e que começara a comprar a sua casa dois anos antes, é tomado como o padrão contra o qual o marido de Silla é medido e achado em falta. As coisas pioram quando, depois que Silla consegue enganar o marido e vender sua propriedade, Deighton revida e destrói os sonhos de propriedade da mulher, gastando o dinheiro da venda em vestuário de luxo e superfluidades para as mulheres da família. Com exceção de Selina, a comunidade Bajan se reúne em condenação do homem que desperdiçara a oportunidade de comprar bens imobiliários, quando tinha todos os rcursos materiais necessários para tanto.

O contraste entre Silla Boyce e os barbadianos que ela representa (os que aceitariam qualquer trabalho, apesar de humilhante, e enfrentariam longas jornadas de trabalho para se tornarem proprietários de uma casa) e Boyce Deighton e os outros homens de Bridgetown, "all the same [...] spree boys" who seem not to know anything about handling money and property and thing so" ${ }^{26}$ lembra a descrição de bell hooks ${ }^{27}$ acerca de duas atitudes contrastantes em relação à vida, testemunhadas por ela em ambientes distintos durante sua infância. O primeiro deles, a casa em que ela própria cresceu, era impulsionado pela orientação capitalista: a posse de bens materiais era o valor dominante. No segundo ambiente, no entanto, também localizado no coração de uma comunidade pobre e negra, as pessoas sustentavam a noção de que seres que saíram da escravidão para a liberdade, ao invés de enfatizar o ter, deveriam se empehar em nutrir o espírito, e criar beleza.

Hooks situa a tentativa de reconhecimento por meio da arte não só no quadro da avaliação contrastante entre ter e ser, mas no cenário histórico de um tempo permeado pela preocupação com a elevação racial, quando as figuras de músicos de sucesso alimentavam as mentes dos negros como modelos viáveis a serem imitados. Em face da noção de que os negros eram incapazes de aprender e de se empenhar em qualquer atividade criativa, músicos famosos eram prova suficiente da falsidade dessa noção. Ante essas pessoas talentosas,

26 MARSHALL, Id., ibid., p. 45.

27 A autora assina sempre com minúsculas. 
os brancos se curvavam em reverência. ${ }^{28}$

Os negros que buscavam reconhecimento por meio da arte expressavam, como também Deighton Boyce o faz, uma versão particular do sonho americano: a crença de que poderiam obter sucesso através de seus próprios méritos na América. No entanto, no caso do pai de Selina, essa crença sofre flutuações e modificaçóes à medida em que experiências de discriminação passadas são evocadas, e ocorrências mais recentes são acumuladas, já que é gradualmente que Boyce se conscientiza de que fora, definitivamente, expulso do lar.

Um primeiro abalo verifica-se quando seu amigo Seifert Yearwood relembra-lhe a existência onipresente do racismo até mesmo em sua terra natal. Dolorosamente, Deighton rememora episódio da juventude, quando trabalho lhe fora negado em Barbados, claramente devido ao preconceito racial. Ao pedir emprego como balconista em uma das grandes lojas de Bridgetown, recebe em retorno olhar de desdém, indignação e incredulidade que distorce a face do inglês branco, que lhe recusa emprego com um seco "não".

Anos depois, na América, após o tumultuado incidente da venda da propriedade em Barbados, Deighton sofre um acidente, o que o torna incapaz de trabalhar, e aniquila para sempre seus planos de um retorno bem-sucedido. $\mathrm{O}$ fim se precipita rapidamente: Deighton sai de casa e, desequilibrado, torna-se um líder espiritual. Silla denuncia sua condição ilegal nos Estados Unidos; segue-se a deportação e um possível suicídio, relatado como queda acidental ao mar, quando já próximo à costa de Barbados.

Para Deighton, que sempre planejara voltar a seu país como um vitorioso, em companhia dos que o amavam e apreciavam também sua terra natal, como sua filha Selina, o retorno sozinho e como pobre deportado é mais do que consegue suportar. Além de humilhante, essa posição frustra todos os seus bem delineados planos. Anula-se o conhecimento vital acumulado, resultante de sucessos e erros passados, deixando-o desprovido de pontos de referênica. Mais: desconstrói-se seu conceito de lar, uma vez que a terra natal é esvaziada da dimensão social significativa; ficam também comprometidos os aspectos referentes a controle e investimento emocional neste ambiente. Assim, como

28 HOOKS, Bell. Yearning: race, gender, and cultural politics. Boston: South End Press, 1990, p. $103-105$. 
Barbados já nao representa o lar de seus devaneios, não faz sentido passar seus dias finais nesse local.

Por outro lado, a gradual realização dos sonhos de propriedade da comunidade Bajan vem a reforçar, para Silla e seus pares, a percepção da América como lar. Como Silla exemplarmente declara, ninguém que tenha vivido em Nova Iorque poderia voltar a morar em sua pequena ilha natal. Gradualmente, o permanente investimento dos migrantes ilhéus na América frutifica: após inicialmente viverem em acanhadas residências no sul do Brooklyn, quando de sua chegada à América em 1920, mudam-se depois para ruas decadentes, como Chauncey St., anteriormente habitadas por cidadâos brancos. Percy Challenor, a personificação do imigrante bem-sucedido de Barbados, torna-se um corretor de imóveis, e abre um grande escritório em Fulton Street, uma rua mais seletiva. Pequenas lojas e negócios pertencentes a barbadianos multiplicam-se, e logo Chauncey St. já não lhes apraz, e passam a morar em belas casas em Crown Heights. A Associação de Proprietários e Empresários de Barbados é fundada, e seu lema, "Não as profundezas de onde viemos, mas as alturas a que nos erguemos", aponta tanto para a destruição do estereótipo do pobre homem de cor que suplica um trabalho a cidadãos brancos, como é evidência de que a comunidade negra Bajan também é capaz de gerir negócios.

Para a geração mais jovem, frequentar a universidade, graduar-se e ter a possibilidade de promover festas de formatura semelhantes às dos brancos vem a cosntituir-se padrão de sucesso na comunidade imigrante. Pressionada por sua mãe, Selina vai para a faculdade. Apesar de se destacar em seu curso de arte, decide abandonar a América. Como sua mãe fizera quando jovem, emigrando de Barbados, onde sentia-se deslocada, Selina decide deixar Nova Iorque para trás, já que a cidade não lhe parece um lar.

Ao final do romance, triste e sozinha, Selina caminha na Fulton St. de sua infância, ao mesmo tempo em que planeja sua mudança para Barbados. Evoca as pessoas que tinha conhecido quando menina, e deseja deixar-lhes alguma recordação: tira então as pulseiras de prata, símbolo de sua herança cultural barbadiana, e as deposita no solo. Esse gesto mostra clara escolha afiliativa do Caribe como lar.

Nesse momento, lar assume uma dimensão pública: ela está se dirigindo para o país de seu pai; contudo, o qualificativo empresta à expressao um certo foro privado. A terra a que se dirige é a que aprendeu a amar através dos relatos 
paternos. Para ela, mais do que um local físico, Barbados é concebido em associação com o fator humano. Portanto, Selina transfere para a terra do pai o amor que sentia por ele, decidindo escolher para si como lar o local que havia assegurado a seu pai seu jeito especial de ser, e que tornara possível a ele ser o homem feliz a quem as pessoas mais materialistas desprezavam, mas a quem ela tanto amava.

\title{
TERRITORIALITY AND IDENTITY NEGOTIATION: THE QUESTIONING OF HOME IN PAULSE MARSHAL'S BROWN GIRL, BROWNSTONES
}

\begin{abstract}
Taking as its object of representation of the AfricanCaribbean migration experience in New York in Paule Marshall's novel Brown Girl, Brownstones, this essay analyzes how place, especially home memories and its lived experience, affect identity construction. After an initial introduction, home is defined and its influences on the formation of individual structural cosmologies are considered before textual analysis proper.
\end{abstract}

KEYWORDS: identity, territoriality, Paule Marshall.

Recebido em: 19/03/12

Aprovado em: 26/11/12 